publication, such omissions are probably intentional.

The book is likely to interest mainly those working or aiming for a career in the various parts of the health information arena. It could also be read with interest by health professionals and non-ethics experts such as the reviewer, as it provides a very readable collection of quotations, a good many of which should cause some argument and debate. The review copy had a number of very small illegible patches which did not however cause any serious problem.

ALEX GATHERER Honorary Director, Medical Risks Studies, Socio-Legal Centre, Wolfson College, Oxford

\section{Parliament and Screening: Ethical and Social Problems Arising from Testing and Screening for HIV and Genetic Disease}

Edited by Wayland Kennet, London, John Libbey and Co Ltd, 1995, 351 pages, Fr168

This is a very useful book, reporting a conference in London, primarily sponsored by the EC, on social and ethical consequences of testing and screening for HIV and genetic disorders, and the roles of parliament and the news media in this. It is recommended for any study in these areas.

An overall impression arising from this book is of the bewilderment of medical, legal and social establishments when facing new crises, and of their need to learn from the past. Although lessons have been learned from prior illnesses, they are not always easily accessible when required in the midst of a crisis. This book will be very useful in reminding the administrators of future epidemics in a coherent and contained form of the lessons that have been drawn thus far from HIV.

A further lesson from this book is how quickly important lessons in the administration of the HIV pandemic in Europe were learned. As the book reveals, positions established in association with the widespread availability of HIV-antibody testing in the mid-1980s have not been challenged to date and appear, with hindsight, to have been both prudent and highly appropriate.

For example, the opening chapter on the ethics of testing and screening for HIV constitutes a re-write of the well-established literature on the mandatory screening debate of the 1980 s. It quickly focuses on the central importance of "reciprocity" in the development of public health responses. Individual civil rights are essential to HIV prevention strategies, and encourage and perhaps reinforce the engagement of the individual within the context of public health imperatives.

There is a concern that a book of ethical discussion must necessarily skate over the considerable dilemmas that challenge and - in the case of HIV - change routine procedures.

For non-lawyers, the revelation that there is no discrete body of principles in common law exclusively relevant to health law comes as something of surprise and is perhaps something that we should be worried about. For example, consent does not rely, in English law, on discussing the implications of a treatment or procedure, although there appears to be a duty of counselling in such instances. A further question is whether the implications of HIV testing, which have long been held as a justification for alterations in "routine" testing procedures, are really as bad as may have been supposed. The shock recognition for this reviewer is that there has been remarkably little empirical quantification, aside from the qualitative anecdotes of the mid to late 1980 s, to support the contention that the differences in implications do merit procedures different from the "norm". There is very little evidence to illustrate just how woolly and complacent legal and professional organisational thinking has been on issues of informed consent and its potential abuses.

The opportunities for the tail of HIV care to wag the dog of establishment thinking and conventional practice in medicine is not as clearly brought out in this book as it might have been, for example in relation to the development and administration of clinical trials. However, a real value in this book lies in the comparison of parliamentary models of response to HIV across the EC states. It is extremely useful, for example, to consider how the burden of proof and informed consent in England rests upon the opinions of health professionals, and not on the opinions of "reasonable, prudent" patients, as in Canada, for example. Developments elsewhere in medicine in this country have revealed how important it can be to consider directly the views of patients in determining the true value of clinical endeavours.

Overall, this book makes for necessary reading, and Lord Kennet and his colleagues are to be commended for laying down footprints in very difficult terrain. It is to be hoped that we can start to learn from the mistakes of the past and economise on the need for the exercise of health legislation in the future.

DR DAVID MILLER

Head: Clinical Psychology Services for HIV/GUM,

Consultant Clinical Psychologist, Honorary Senior Lecturer, UCL Medical School, London

\section{Zur Verantwortung des Arztes}

Urban Wiesing, Stuttgart-Bad Cannstatt, Frommann-Holzboog, 1995,190 pages, 58.00

Deutschmarks

"What responsibilities can reasonably be ascribed to physicians?" In his recently published book $\mathrm{Zur}$ Verantwortung des Arztes (On the Responsibility of the Physician), Urban Wiesing, a physician and philosopher, attempts to give an answer to this fundamental question. He focuses on diagnostic-therapeutic processes, since they have a normative character and are thus well suited to his investigation, which starts by examining the role of the physician and the epistemological status of modern medicine. The method employed is a so called "reconstructive approach", which starts from the present conception of the role of the physician, and then questions the extent to which this conception is plausible, consistent and applicable. The physician has the responsibility to act in specific situations in a specific manner. In doing this the physician has only limited information and is under pressure to make decisions. Furthermore the physician cannot guarantee the success of his or her actions, and does not even know whether the outcome is the result of his or her intervention or not. 